\title{
Socially Empowered Learning in the Classroom: Effects of Arts Integration and Social Enterprise in Schools
}

Brittany Harker Martin

University of Calgary

Ann Calvert

University of Calgary

\begin{abstract}
This paper tests a new theoretical framework for engaging students by evaluating two project-and-design-based pedagogies: Arts Integrated Collective Creation (AICC) and Educational Social Enterprise (ESE). Findings provide statistical support for benefits with middle school students when instruction is designed around Socially Empowered Learning (i.e., group-based, creative agency, real-world issues, and positive social impact). We advance the theory of Socially Empowered Learning (SEL) in identifying and finding empirical support for a novel instructional approach with strong effects and implications for the power of the arts to enhance cross-curricular learning.
\end{abstract}

\section{Introduction}

A growing trend in education shows schools transforming into forums of social action where students design social impact projects in response to real-world issues. In some cases, teachers use Arts Integrated Collective Creation (AICC) with students exploring topics in the core subjects (e.g., social studies or language arts) as they create performances through the arts (integrating dance, drama, visual arts, and music). In other cases, teachers use Educational Social Enterprise $(E S E)$ with students exploring social issues as they create innovative solutions to identified social needs. Such pedagogical innovations may be driven by teacher response in recognition that traditional learning methods (i.e., reading, writing, and worksheets) are not meeting the needs nor interests of the majority of a diverse student population (Willms, Friesen, \& Milton, 2009). In fact, nation-wide research in Canada on more than 70,000 students reported fewer than $40 \%$ are intellectually engaged (Dunleavy, Milton, \& Willms, 2012). Similar findings on engagement are reported in other countries around the world (Anyon \& Naughton, 2003; Organisation for Economic Co-operation and Development [OECD], 2012) echoing the concern that something 
must be done to increase engagement in schools. Disengagement of this kind can fuel further disengagement (Bandura, 1982; Pope, 2001), and students with potentially bright futures may not see the value of their school experience and lose interest (Csikszentmihalyi, Rathunde, \& Whalen, 1997; Lee \& Anderson, 1993). Worse, students who are not intellectually engaged may not achieve levels of knowledge required for success as adults (Dunning, 2008, as cited in Willms et al., 2009). We frame this mass disengagement as collective powerlessness requiring intervention. AICC and ESE may offer potential solutions; yet, to date, little empirical research has been undertaken to measure these effects.

The purpose of this study is to empirically measure instructional practices, namely AICC and ESE, as potential interventions for increasing student intellectual engagement. In doing so, the study evaluates a relatively new theoretical framework, the Socially Empowered Learning Framework (SELF), in practice while providing much needed empirical data on pedagogical innovations. First, we summarize the theoretical underpinnings of SELF, derived from three streams of psychology (Martin, in press). Then, we present hypotheses and describe the method used to test the theoretical framework in practice, after which we present and discuss our findings. Last, we discuss implications for future theoretical development with recommendations for teaching and learning. Ultimately, we aim to influence positive change in the lives of students by providing empirically tested ways to design instruction that engages their minds, fosters their entrepreneurial spirit, and empowers them to make a difference in the world.

\section{Theoretical Framework}

Socially Empowered Learning (SEL) is defined as "group-based, creative and agency-rich projects that address real-world issues and make a positive social impact" (Martin, in press). SEL is not a teaching strategy itself, but a theoretical and conceptual framework for instructional design that incorporates all four requirements of the definition (i.e., group-based, creative agency, real-world issues, and positive social impact). These requirements were derived from unifying three streams of psychology: positive psychology, social learning theory, and social psychology (Martin, 2014).

\section{Positive Psychology's Flow and Social Learning Theory's Efficacy}

Intellectual engagement is different from traditional notions of engagement. It is a relatively new construct, defined as "a serious emotional and cognitive investment in learning, using higher-order thinking skills to increase understanding, solve complex problems, or construct new knowledge" (Willms et al., 2009, p. 7). Intellectual engagement is a shift from the mainstream studies on engagement that rely on levels of attendance, extra-curricular activities, social relationships at school, and general motivation as measures of engagement (Eccles \& Barber, 1999; Wang \& Eccles, 2012). Such measures, although useful within their context, do not inform instructional interventions that specifically target students who are not motivated to do well, do not show a sense of interest, and do not feel their schoolwork is relevant (Willms et al., 2009). ${ }^{1}$

\footnotetext{
${ }^{1}$ While Willms et al.'s (2009) research was conducted to measure the levels of intellectual engagement in mathematics and language arts, it serves to highlight a potential crisis within the institution of schooling.
} 
SEL is hypothesized to increase intellectual engagement through a construct that comes from positive psychology: flow. Flow is a deep absorption in an intrinsically interesting activity (Csikszentmihalyi \& Csikszentmihalyi, 1988; Willms et al., 2009). Flow occurs when there is balance between an individual's perceived challenge in a task and that person's perceived skills to accomplish it (Bakker, 2005; Csikszentmihalyi, 1997; Hunter \& Csikszentmihalyi, 2003; Shernoff, Csikszentmihalyi, Schneider, \& Shernoff, 2003). Figure 1 below (adapted from Willms et al., 2009) illustrates the student experience based on different combinations of perceived challenge and skills. As indicated, students who perceive a high level of challenge but low skills to achieve it (top left), experience anxiousness and apprehension in the learning task. These students typically do not like a learning task because they find it too hard. In contrast, students who perceive a low level of challenge but high skills to achieve it (bottom right) experience boredom in the learning task, despite willingness and ability to accomplish it.

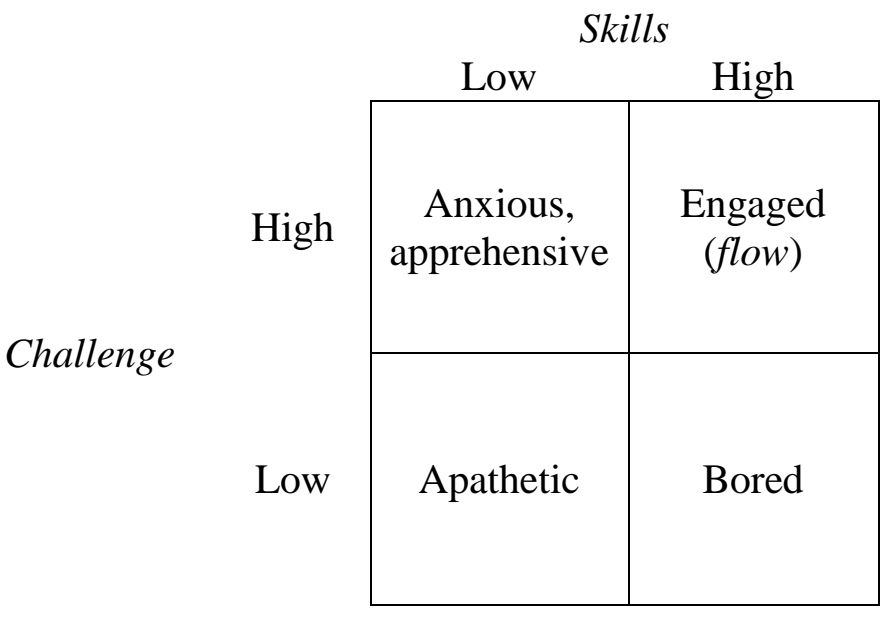

Figure 1. Student experience based on perceived challenge \& skills. Adapted from What did you do in school today? Transforming classrooms through Social, Academic, and Intellectual Engagement by J. D. Willms, S. Friesen, and P. Milton. Copyright 2009 by the Canadian Education Association.

For students who perceive both challenge and skill as low (bottom left), their consequential experience with the task is one of apathy. Of particular relevance to intellectual engagement are students who perceive an appropriate balance between high challenge and high skill (top right). These students are motivated in such a way that they are intrinsically compelled to engage with a task, sometimes on a level so deep they can lose track of time.

Flow describes the experience when someone is completely engaged, and although it is not always achieved (in fact is quite uncommon), it serves as a guide for optimal engagement. The question remains: how do teachers design learning to motivate such engagement? The answer may be found in another branch of psychology, by comparing positive psychology's theoretical balance of challenge and skill for flow with social learning theory's theoretical balance of challenge and self-efficacy for motivation. 
Self-efficacy is a perception of how well one can execute the courses of action required to deal with prospective situations (Bandura, 1982, 1997, 2001). It is not based on actual skills, but on the perception or confidence in one's skills relative to being able to cope with a task (Fiske \& Taylor, 2013). People are motivated to engage in or avoid an activity based on their perceived selfefficacy (Bandura, 2001). According to Baumeister and Finkel (2010), "when people believe that they can exert control in the sense of having confidence that they can make the desired response, they are better able to actually make that response" (p. 714).

Learners with a perceived high self-efficacy exert more cognitive effort with tasks considered difficult and less effort on things they consider easy (Bandura, 1982; Salomon, 1984). Figure 2 illustrates the predicted behavioral response to perceptions of self-efficacy and challenge.

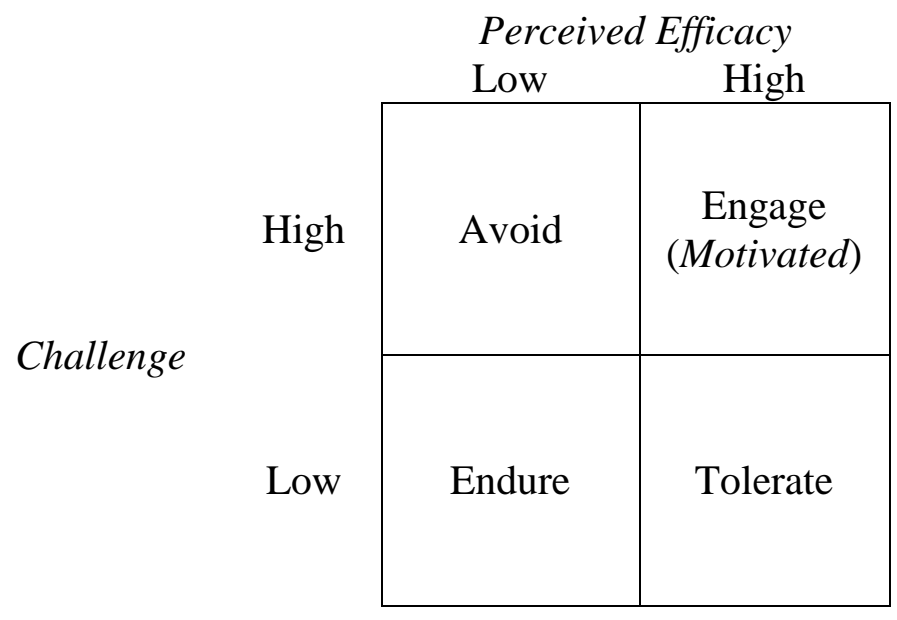

Figure 2. Behavioral response based on perceived challenge and efficacy.

Figure 2 shows how perceptions mediate the relationship between knowledge (what we know about ourselves and a task) and action (what we do). Students who perceive their self-efficacy to be low in relation to a perceived high level of challenge (top left) are unmotivated and may avoid the task in dysfunctional ways (Bandura, 1982, 1989; Dweck, 1975, 2006; Dweck \& Leggett, 1988). On the other hand, students who perceive their level of self-efficacy to be high in relation to a perceived low level of challenge (bottom right) are unmotivated because they are required to exert the minimal cognitive effort and tolerate the mediocrity. Students who perceive their selfefficacy to be low, in relation to a perceived low level of challenge (bottom left) are also unmotivated and must endure learning in a way that is even more debilitating to self-efficacy through experiencing failure repeatedly (Bandura, 1982). Only when perceived efficacy and challenge are both high (top right) are students predicted to be motivated and engage.

It is important to note that efficacy is not static and can be raised or lowered based on experience. "Successes heighten perceived self-efficacy; repeated failures lower it" (Bandura, 1982, p. 126). In this way, social learning theory frames the relationships between challenge and skill slightly differently than positive psychology, because it predicts behavioral motivation to 
engage, rather than predicting the individual's experience of engagement. Both theories, however, predict that when confidence in one's ability is high and challenge is appropriately matched, students will engage. Likewise, both theories predict that when these are not appropriately matched, students will not engage. The instructional imperative for teachers, then, is to design learning tasks in such a way that students have the opportunity to experience success within conditions of balanced self-efficacy and challenge. According to Bandura (2000a), if this balance can be achieved, students will be intrinsically motivated to engage with the task in pursuit of mastery.

\section{From Flow and Efficacy to Social Empowerment}

One way that teachers can increase a student's self-efficacy is by increasing it through collective efficacy: a shared belief in collective power to produce desired results (Bandura, 2000a, 2001). Social learning theory research shows that collective efficacy can be increased through positive experience with social activism, as a group, especially for individuals in circumstances that seem socially unjust (Bandura, 1982, 2000a, 2000b, 2001; Fernández-Ballesteros, DíezNicolás, Caprara, Barbaranelli, \& Bandura, 2002). According to Bandura (2000a, 2000b, 2001), this group level effect is task specific, but another theory from social psychology proposes that the group's overall sense of empowerment can be increased and sustained over time. Thus, we turn to social psychology for an understanding of the construct of group potency (Guzzo, Yost, Campbell, \& Shea, 1993; Stajkovic, Lee, \& Nyberg, 2009).

Group potency is "the collective belief in a group that it can be effective, and its role in determining group effectiveness" (Guzzo et al., 1993, p 12). Unlike collective efficacy, group potency is based on shared perceptions about the group that are not task specific, and instead reflect perceived overall effectiveness of the group. In this way, potency helps explain why collective efficacy increases through experience with positive social change. Shared beliefs in the group's ability increase with every success over time.

Together, collective efficacy and group potency create a new way to measure empowerment (i.e., one's perceived confidence in abilities and agency to achieve something) as a shared measure called social empowerment. These variables also explain how designing learning to increase efficacy and potency through group-based social action can create conditions similar to those required for flow. Hence, SELF proposes that social empowerment mediates the relationship between program design and intellectual engagement, as illustrated in Figure 3. 


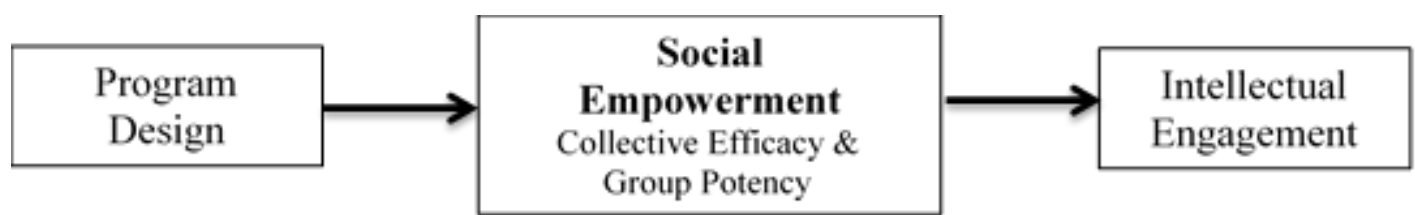

Figure 3. The mediating relationship between program design and intellectual engagement via social empowerment.

As seen in Figure 3, social empowerment embodies a group's perceived confidence with the task at hand, as well as a group's perceived confidence in its ability to perform future, unrelated tasks; an increase in social empowerment is predicted to increase student intellectual engagement.

\section{Entrepreneurial Spirit as Consequent and Mediator in the Model}

Figure 3 illustrates the basic relationship between instructional design and intellectual engagement as mediated by social empowerment. The construct of social empowerment is based on designing the opportunities for agency to take action and shape the outcome (Fisk \& Taylor, 2013). This leads to another consequent construct within the model: entrepreneurial spirit. This construct employs a design-based notion of entrepreneurial, a self-directed and innovative set of capabilities in mandates of government education agencies that, in turn, challenges teachers to find ways to teach it.

Entrepreneurial spirit is a relatively new construct that has emerged from a variety of sources and disciplines, aligning with the trend of entrepreneurial programs in schools that foster the mindset and skills to initiate opportunity, take risks, and be resilient to life's challenges. (Martin, in press).

SELF predicts that, once motivated to act, socially empowered students experience conditions ripe for developing entrepreneurial spirit, an orientation towards taking the initiative to innovate, take risks and make bold decisions in the face of adversity (Athayde, 2009; Bonnett \& Furnham, 1991; Martin, in press; Mbebeb, 2009).

The stronger the perceived collective efficacy, the higher the group's aspirations and motivational investment in their undertakings, the stronger their staying power in the face of impediments and setbacks, the higher their morale and resilience to stressors, and the greater their performance accomplishments. (Bandura, 2001, p. 14)

Anecdotally, this presents as a can-do attitude where students are undaunted by challenges before them, even on a global scale. 


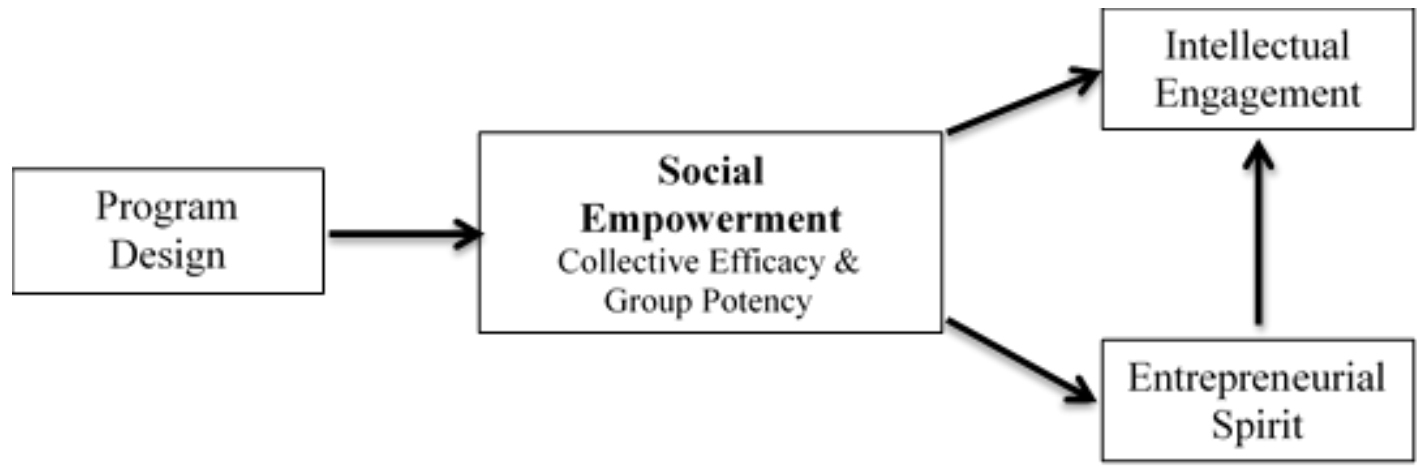

Figure 4. Variables and relationships of socially empowered learning.

There is empirical support for the relationships between social empowerment, entrepreneurial spirit and intellectual engagement using SELF as set out in Figure 4 (Martin, in press), which supports the proposition that socially empowered learning is a powerful tool for predicting, measuring, and increasing intellectual engagement.

The present study focuses on the instructional design aspect of the SELF model. Specifically, it is hypothesized that the instructional practices embedded in AICC and ESE programs will enhance social empowerment, and thus enhance entrepreneurial spirit and intellectual engagement.

\section{Methodology}

This study employed a one-way within-and-between-subjects quasi-experimental design. Participants were students in grades 5/6, 6, and 7, recruited from four schools in a large Calgary school district. Three of the schools received a program designed using either AICC, ESE, or a combined program of both AICC and ESE. ${ }^{2}$ The fourth school served as a wait-list control. Before and after the program, students completed a survey using measures of the constructs of socially empowered learning.

Students receiving the AICC intervention participated in Trickster Theatre, an experience that explored a global issue using music, drama, dance, and art to create a performance together. This was offered to 57 students (accounting for $17.8 \%$ of the overall sample), and took the form of art making, improvisational theatre games, collective choreography, and set and costume design, through which students explored global topics from different roles and generated episodes that were scripted, rehearsed, and performed for a community audience. Students receiving the ESE intervention participated in Kids Go Global, an experience that explored a global issue using a website and entrepreneurial coaching to collaborate with non-government organizations and fundraise for social need. This was offered to 65 students (accounting for $20.2 \%$ of the overall sample), and took the form of business venture design and execution, through which students

\footnotetext{
2 The Trickster Theatre and Kids Go Global programs are both good examples of Socially Empowered Learning because they are group-based,
} with opportunity for creative agency that explore real-world issues, and focus on making a difference in the world. 
learned about a global issue (e.g., access to clean water) and created a social enterprise to generate funds for the cause. Students receiving the combined intervention participated in Trickster Theatre and Kids Go Global delivered in tandem. This combined program was offered to 79 students (accounting for $24.6 \%$ of the overall sample), and took the form of students exploring a global issue through the arts, in such a way that they created a script to be performed, while also designing a social venture to raise funds for the cause. Since students in the fourth school group served as a wait-list control, they did not receive a program until after the final data collection (offered at no cost in compensation for time and participation in the research project). This group was made up of 120 students, accounting for $37.4 \%$ of the overall sample. Table 1 shows the student and treatment distribution (post-measures).

\section{Table 1}

SELF Research Project 2014 Student and Treatment Distribution

\begin{tabular}{cccc}
\hline \hline School & Intervention Method & $\begin{array}{c}\text { Students } \\
(N=321)\end{array}$ & $\%$ \\
\hline \hline School 1 & AICC & 57 & 17.8 \\
School 2 & ESE & 65 & 20.2 \\
School 3 & Combined & 79 & 24.6 \\
School 4 & Control & 120 & 37.4 \\
\hline
\end{tabular}

\section{Participants}

Using a quasi-experimental design, students participating in these interventions were measured in the fall of 2013 and in the spring of 2014. Participants in the treatment groups received the intervention for approximately 15 visits across 6 months. All participants completed a pre- and post-treatment survey. It should be noted that the pre- and post-measures followed identical procedures. The pre-measure sample was 359 students consisting of 192 males (53.5\%) and 167 females (46.5\%). The post-measure sample was 321 students consisting of 168 males (52.3\%) and 153 females (47.7\%). A total of 202 participants identified English as a first language (63\%) and 119 identified English as a second language (37\%). These demographics are very close to those found in the pre-test data and as such suggest that the attrition from 359 to 321 was evenly distributed across demographic characteristics.

\section{Measures and Procedure}

Psychometric scales were designed to measure the effects of program interventions that manipulated the model variables. For pre- and post-measures, all participants used school computers to complete an online survey under the supervision of the primary researcher and a research assistant. The researcher provided an overview of the instructions, and then students completed the items independently. When students had questions, they were invited to raise their hands and the researcher or research assistant addressed them. In most cases, students sought 
definitions for specific words. To address this issue, common definitions were provided to all students who participated.

A series of demographic items was followed by measures of social empowerment based on a 13-item summary scale of two scales: collective efficacy and group potency. The guidelines provided for measurement by Bandura (2006) were the basis for a collective efficacy measurement (percentage scale) asking students how well, working as a group, they believed they could complete certain tasks such as, "change the world". The collective efficacy scale had an internal consistency in this sample of .88 assessed by Cronbach's alpha. Group potency was measured using a modified form of Guzzo et al.'s (1993) group potency measure (a 5-point Likert-type scale ranging from "never" to "all of the time"). The scale was modified to focus respondents on the group level as a class (e.g., instead of "my team" they considered "my class"). This scale had an internal consistency in this sample of .81 assessed by Cronbach's alpha. The summary scale created for social empowerment that combined these two sub-scales had an internal consistency in this sample of .84 assessed by Cronbach's alpha (indicating a reliable new measure). Of note, the two sub-scales were highly correlated $(r=0.51)$. In order to create the summary scale, the scores on each scale were standardized because of the different types of responses to them (i.e., percentage for collective efficacy and 1-5 for group potency). Then the average of these standardized scores was taken.

Entrepreneurial spirit was measured using seven items from Athayde's (2009) Attitudes Toward Enterprise (ATE) test and included items related to creativity, leadership, personal control, and achievement. This scale showed an internal consistency in this sample of .46 assessed by Cronbach's alpha. Although the reliability score for this scale is relatively low, due to concerns about respondent fatigue, we chose not to include more items (which we address in the limitations section of this paper). Students responded to items, rating the extent to which they agreed with statements using a 1 (strongly disagree) to 5 (strongly agree) Likert-type scale.

To measure intellectual engagement, we created a new scale using 16 items from Daniels, Friesen, Jacobsen, and Varnhagen (2012), including items such as "I try to do my best because I want a good mark," "I spend a lot of time day-dreaming, socializing, or pretending to pay attention" (reverse coded), and "I wish we did not have to take the class/subject" (reverse coded). This scale included items measuring flow and showed an internal consistency in this sample of .78 assessed by Cronbach's alpha.

\section{Data Preparation}

After removing cases that had more than $10 \%$ of the data missing duplicates, and following a match to the pre-test student I.D. number, a total of 321 cases for the post-test were available for analyses. There were 13,482 possible data points for the non-demographic responses to the scaled items. Only 112 of these points $(0.8 \%)$ were missing, and those were evenly distributed throughout the data set. Missing data points were substituted with the middle point on the scales (i.e., " 3 " for Likert-type; $n=96 ; 50 \%$ for the percentage scale; $n=6$ ). Thus, all analyses were based on 321 cases. Students in the 5/6 split class were collapsed into the Grade 6 category. 


\section{Results}

\section{Descriptive Statistics}

Descriptive statistics for the scales are presented in Table 2. The average scores for engagement were slightly above the centre point on the scales, but the means did not show excessive skew and the standard deviations indicated reasonable variance.

\section{Table 2}

Descriptive Statistics for the Post-test Scales

\begin{tabular}{lcc}
\hline Scale & $M$ & $S D$ \\
\hline Social Empowerment & 0.03 & 0.84 \\
Engagement & 3.87 & 0.49 \\
Entrepreneurial Spirit & 3.28 & 0.51 \\
\hline
\end{tabular}

No separate tests of demographic variables on the variables of interest were conducted with the post-test data. It was assumed that these variables would have similar (small, but significant) effects on the scales of interest as those found in the pre-test data, and so were controlled for in the analyses.

Test of treatment effects. Assessments of the effects of the educational programs on the variables of interest were conducted using an analysis of covariance (ANCOVA). As per Arvey and Cole (1989), this approach provides both the highest power as well as handling the effects of pre-test scores in the assessment of the differences between treatment groups when evaluating change resulting from formal interventions.

In the ANCOVA, the pre-test scores were used as a covariate. These analyses partial out the pre-test scores and then examined differences between the groups on the post-test. In addition to the pre-test scores on the relevant variables, the demographic variables of gender, grade, and language were also added as covariates. Table 3 shows the results of these analyses with the effects of the treatment groups shown. A $p$-level of $<.10$ was adopted given the relative lack of empirical studies in this area and the importance of reporting on marginally significant effects to assist in moving the field and area of inquiry forward.

Follow-up tests using Bonferroni corrections indicated that: (a) social empowerment under the ESE treatment was higher than for AICC alone ( $p=.039)$ and for control $(p=.025)$, and was highest under the combined treatment; (b) entrepreneurial spirit under the combined treatment was higher than for the ESE treatment and the control group ( $p=.052)$; and (c) intellectual engagement under the combined treatment was higher than for AICC alone ( $p=.007)$. 
Table 2

ANCOVA Results - Treatment Effects and Post-Test Statistics

\begin{tabular}{|c|c|c|c|c|c|c|c|c|c|c|}
\hline \multirow[b]{2}{*}{ Variable } & \multicolumn{2}{|c|}{ AICC } & \multicolumn{2}{|c|}{ ESE } & \multicolumn{2}{|c|}{ Combined } & \multicolumn{2}{|c|}{ Control } & \multirow[b]{2}{*}{$F$} & \multirow[b]{2}{*}{ sig. } \\
\hline & $M$ & $S D$ & $M$ & $S D$ & $M$ & $S D$ & $M$ & $S D$ & & \\
\hline $\begin{array}{l}\text { Social } \\
\text { Empowerment }\end{array}$ & -0.23 & 0.86 & 0.23 & 0.72 & 0.32 & 0.84 & -0.16 & 0.81 & 4.185 & .006 \\
\hline $\begin{array}{l}\text { Intellectual } \\
\text { Engagement }\end{array}$ & 3.66 & 0.49 & 3.85 & 0.54 & 4.04 & 0.51 & 3.85 & 0.41 & 3.696 & .012 \\
\hline $\begin{array}{l}\text { Entrepreneurial } \\
\text { Spirit }\end{array}$ & 3.18 & 0.44 & 3.26 & 0.61 & 3.46 & 0.51 & 3.20 & 0.46 & 2.520 & .058 \\
\hline
\end{tabular}

Pairwise Comparisons. Paired-sample t-tests for each school (treatment) were conducted to assess whether there was any change in mean scores (before and after the program) on the variables of interest. For the ESE treatment, there were significant increases in: (a) social empowerment from pre-test $(M=0.06, S D=0.75)$ to post-test $(M=0.23, S D=0.72), t(64)=-2.849$, $p=.006$; (b) engagement from pre-test $(M=3.63, S D=0.50)$ to post-test $(M=3.85, S D=0.54)$; $t(64)=-3.261, p=.002$; and (c) entrepreneurial spirit from pre-test $(M=3.01, S D=0.55)$ to post-test $(M=3.26, S D=0.61) ; t(64)=-3.592, p=.001$. For the AICC treatment, there was a significant increase in entrepreneurial spirit from pre-test $(M=2.97, S D=0.52)$ to post-test $(M=3.18, S D=0.44)$; $t(56)=-3.049, p=.004$. For the combined treatment, there was a significant increase in entrepreneurial spirit from pre-test $(M=3.26, S D=0.55)$ to post-test $(M=3.46, S D=0.51)$; $t(78)=-2.747, p=.007$.

\section{Discussion}

This paper began with a call for intervention and purpose to identify and measure socially empowered interventions in practice in order to provide empirically-tested ways to design instruction that increases intellectual engagement. Findings here reveal that SEL is an effective way to increase intellectual engagement, and that different instructional approaches have unique effects on different variables in the framework.

For results on social empowerment, it was somewhat of a surprise that ANCOVA findings showed it only increased in groups who received ESE and the combined treatment. Pairwise comparisons showed that ESE significantly increases social empowerment within subjects. Social empowerment did not increase from AICC alone, and the arts educators on our team found this disheartening. Perhaps it is because the real-world impact of a dramatized performance is less tangible than taking action for a cause? Perhaps it is in the way we measured social empowerment as perceived impact in the world? More research is required to delve deeper into this line of inquiry. However, of equal intrigue was the finding that the highest scores on social empowerment came from the combined treatment. This suggests that there are benefits only attainable when an ESE 
initiative is enhanced by arts integration. Whether or not this is effect is combinative or additive in nature requires further investigation. Nevertheless, it is strong evidence that social empowerment is higher when social change initiatives include exploration and expression through the arts.

One possible explanation for this is that AICC provides the opportunity to explore the perspectives of others. In doing so, it connects students to the social cause in a way that increases social empowerment when combined with the opportunity to do something about it. In short: the inherent opportunity for empathy in AICC may act as a fuel injector to boost the effects of ESE in such a way that scores on social empowerment are higher than with ESE alone. ${ }^{3}$

The big surprise in our findings was the powerful effect all forms of SEL had on levels of entrepreneurial spirit. We expected to see an effect from the ESE, especially given the entrepreneurial aspects embedded within the process. We were, however, intrigued to see a similar jump in AICC and in the combined treatment program. Such findings have immediate implications for practice, where teachers are being asked to design learning around a concept so new that there are few resources on how to teach it. Findings here indicate that play-building and social enterprise activities, on their own or together, will develop entrepreneurial spirit in students through an avenue of social empowerment. Further, ANCOVA results showed that entrepreneurial spirit under the combined treatment had the greatest effect, in line with the findings for social empowerment.

ANCOVA results showed that intellectual engagement was higher with ESE than with AICC and highest in the combined treatment. In fact, the only statistically significant increase on this variable, in the ANCOVA results, was seen in the combined treatment. Pairwise comparisons showed that ESE increased intellectual engagement within subjects (change in students from a before and after program perspective). Yet, the arts integrated instruction did have a positive effect on intellectual engagement when it was provided in combination with instruction that provided the opportunity to create social value. Again, we see evidence that in order to capitalize on the greatest benefits for intellectual engagement, ESE and AICC must be delivered together. This could be partially due to the intellectual engagement students experience when immersed in artistic production (Sefton, 2006), but it also means taking artistic activities one step further to include an element of social action. In this way, students will still experience the many benefits of arts integration, including the opportunity to express themselves creatively while pedagogically increasing the likelihood of a positive impact on engagement.

In a similar vein, ANCOVA results show that the greater increase in entrepreneurial spirit came from the combined treatment. Pairwise comparisons found that all three treatments, including the AICC and ESE pedagogies, significantly increased entrepreneurial spirit - but again, the greatest increase was seen when they were delivered together. It is a recurrent finding that the

\footnotetext{
${ }^{3}$ Higher scores on empathy would have supported this, but the single-item measure was limited and requires modification in order to inform results.
} 
combined treatment had the greatest effect and a data-informed, successful form of SEL is identified: Educational Arts-based Social Enterprise (EASE). ${ }^{4}$

Thus, the theoretical, requisite elements of SEL are empirically supported, and we identify a powerful form of instruction for increasing intellectual engagement in the middle years through EASE. There is ample empirical evidence to support the claim that learning designed around social value initiatives increases intellectual engagement, and that this learning is most effective when the design integrates learning through the arts where artistic processes enhance student connection to social context. Students who have the opportunity to: (a) learn about the social circumstances of others; (b) express and advocate in response to them; and (c) take action and create an observable impact, will be in conditions that are prime for increased social empowerment, entrepreneurial spirit, and intellectual engagement.

\section{Limitations}

The low reliability of the scale for entrepreneurial spirit was not surprising, given that the original scale had multiple dimensions. However, this does limit the study in creating issues of validity. Since the relationships we found were significant, even with low reliability, theoretically improving the psychometrics for this variable should only strengthen the relationships found. Still, we believe some items within this scale more accurately reflected our intended construct than others, and propose that future research fine-tune the scale to better fit the leadership and agency aspects of entrepreneurial behavior.

On a different note, $39 \%$ of the students spoke English as a Second Language (ESL), and $20 \%$ of students spoke Filipino. Unstated cultural beliefs and assumptions may have influenced perceptions in ways researchers were unaware. To prevent possible issues of misinterpretation or misunderstanding of terms, researchers provided common definitions for potentially challenging vocabulary, and encouraged students to raise their hands and ask for definitions of unfamiliar words. However, this was only effective in cases where students raised their hands and asked for clarification.

The fact that the sample was composed of urban students with a high immigrant population could limit generalization. Future research in rural, remote, and other urban locations (across Canada and internationally) would help to address this issue. Further, individual variability, considered by some to be influential in students' ability to engage and experience success, is another possible limitation. Although the large sample size theoretically reconciles effects from individual differences, it still may be considered as a limiting factor.

The use of individual perceptions as the unit of observation for measures of group-level constructs (the unit of analysis for collective efficacy and group potency) complicates the analyses, since the unit of analysis for all other variables is at the individual level, aggregated for betweengroup comparisons. This is an acceptable limitation from using previously designed and tested metrics, given the authenticity of the sources and lineage of reliability (Bandura, 2006; Willms et

\footnotetext{
4 At the time of this study, the combined treatment as delivered by Trickster Theatre and Kids Go Global was an exemplary example of this kind of instruction, though others certainly exist.
} 
al., 2009). Lastly, using multiple self-report scales can be a limitation due to common method variance; however, given the exploratory nature of the study and the fact that the sample was composed of middle school students with associated concerns of confidentiality, this methodology was deemed acceptable.

\section{Future Research}

While dialogical practices have been an integral aspect of arts education research for years, the particular features of this study bring a number of facets to bear simultaneously, and consider their effects through a quantitative lens. SELF is designed around psychological constructs that are applicable to any level, from preschool to post-secondary, with the potential to research the general trend of disengagement. Future research should focus on measuring the impact of SEL in a variety of contexts, including post-secondary education and the workplace. It should also focus on identifying more programs and instructional practices that are happening in schools as SEL practices in order to reap the benefits identified here (e.g., international trips focused on building schools or volunteer work, community engaged service-learning, social entrepreneurship, etc.). Future research can contribute to the discussions in arts education by considering the processes within social empowerment's collective efficacy and group potency from an arts-based perspective that draws upon aspects of reflection, perspective taking, and art making. Regarding the framework itself, there is opportunity to further develop the scales of the model, including the addition of well-developed scales on empathy and ethical reasoning, proposed as antecedent to social empowerment in the original framework (Martin, 2014, in press). Last, findings here have sparked intrigue into the mediating effect of entrepreneurial spirit on intellectual engagement, suggesting future breakdown of this construct to further investigate its relationship with empowerment.

\section{EASE in Practice}

Planning SEL as Educational Arts-Integrated Social Enterprise (EASE) requires designing learning and instruction with the definition and research findings in mind. First, activities should be group-based in order to capitalize on the effects of collective efficacy and group potency to empower the group. Second, it is critical that these activities offer creative challenges for students through the arts (i.e., art, dance, drama, and music) to create optimal conditions for agency, perspective taking and flow. Third, the learning should address real-world issues explored through multiple perspectives and provide opportunity to design social change initiatives that make an observable impact. Real-world issues connect students to society and provide an authentic platform to consider the ethical complexities of determining what is right and wrong. Fourth, experiences need to provide an opportunity to make positive social change. This final requirement is essential in order to create conditions for developing collective efficacy and group potency while the act of making the change increases entrepreneurial spirit, and thereby intellectual engagement. 


\section{Conclusion}

This study provides empirical support for the emerging theory of SEL while contributing to the new stream of research that focuses specifically on intellectual engagement and instructional intervention. In addition, it contributes much needed empirical, quantitative data on the effects of arts integration and educational social enterprise in schools.

In conclusion, this work employs a new theoretical model and complex statistical analyses to analyze trending pedagogies in practice while providing data-driven recommendations for intervention for low intellectual engagement. Findings support hope for currently disengaged youth and future levels of intellectual engagement in the form of instruction that creates conditions for students to empower and engage themselves.

\section{References}

Anyon, Y., \& Naughton, S. (2003). Youth empowerment: The contributions and challenges of youth-led research in a high-poverty, urban community. Stanford, CA: John W. Gardner Center for Youth and their Communities.

Arvey, R. D., \& Cole, D. A. (1989). Evaluating change due to training. In I. Goldstein (Ed.), Frontiers of industrial and organizational psychology: Training and career development (pp. 89-118). San Francisco, CA: Jossey-Bass.

Athayde, R. (2009). Measuring enterprise potential in young people. Entrepreneurship Theory and Practice, 33(2), 481-500.

Bakker, A. B. (2005). Flow among music teachers and their students: The crossover of peak experiences. Journal of Vocational Behavior, 66(1), 26-44.

Bandura, A. (1982). Self-efficacy mechanism in human agency. American Psychologist, 37(2), 122-147.

Bandura, A. (1997). Self-efficacy: The exercise of control. New York, NY: Freeman.

Bandura, A. (2000a). Exercise of human agency through collective efficacy. Current Directions of Psychological Science, 9, 75-78.

Bandura, A. (2000b). Perceived self-efficacy in cognitive development and functioning. Educational Psychologist, 28(2), 117-148.

Bandura, A. (2001). Social cognitive theory: An agentic perspective. Annual Review of Psychology, 52(1), $1-26$.

Bandura, A. (2006). Guide for constructing self-efficacy scales. In T. Urdan \& F. Pajares (Eds.), Selfefficacy beliefs of adolescents (pp. 307-337). Charlotte, NC: Information Age Publishing.

Baumeister, R. F., \& Finkel, E. J. (Eds.). (2010). Advanced social psychology: The state of the science. New York, NY: Oxford University Press.

Bonnett, C., \& Furnham, A. (1991). Who wants to be an entrepreneur? A study of adolescents interested in a young enterprise scheme. Journal of Economic Psychology, 12(3), 465-478.

Csikszentmihalyi, M. (1997). Finding flow: The psychology of engagement with everyday life. New York, NY: Basic Books.

Csikszentmihalyi, M., \& Csikszentmihalyi, I. S. (Eds.) (1988). Optimal experience: Psychological studies of flow in consciousness. Cambridge, UK: Cambridge University Press.

Csikszentmihalyi, M., Rathunde, K., \& Whalen, S. (1997). Talented teenagers: The roots of success and failure. Cambridge, UK: Cambridge University Press.

Daniels, J., Friesen, S., Jacobsen, M., \& Varnhagen, S. (2012). Technology and high school success research: Final report. Retrieved from http://education.alberta.ca 
Dunleavy, J., Milton, P., \& Willms, J. D. (2012). Trends in Intellectual Engagement (Research Report No. 3). Toronto, ON: Canadian Education Association. Retrieved from https://www.edcan.ca/wpcontent/uploads/cea-2012-wdydist-report-3.pdf

Dweck, C. S. (1975). The role of expectations and attributions in the alleviation of learned helplessness. Journal of Personality and Social Psychology, 31(4), 674-685.

Dweck, C. S. (2006). Mindset: The new psychology of success. New York, NY: Random House.

Dweck, C. S., \& Legget, E. L. (1988). A social-cognitive approach to motivation and personality. Psychological Review, 95(2), 256-273.

Eccles, J. S., \& Barber, B. L. (1999). Student council, volunteering, basketball, or marching band what kind of extracurricular involvement matters? Journal of Adolescent Research, 14(1), 10-43.

Fernández-Ballesteros, R., Díez-Nicolás, J., Caprara, G. V., Barbaranelli, C., \& Bandura, A. (2002). Determinants and structural relation of personal efficacy to collective efficacy. Applied Psychology, $51(1), 107-125$.

Fiske, S. T., \& Taylor, S. E. (2013). Social cognition: From brains to culture. Thousand Oaks, CA: Sage.

Guzzo, R.A., Yost, P. R., Campbell, R. J., \& Shea, G. P. (1993). Potency in groups: Articulating a construct. British Journal of Social Psychology, 32, 87-106.

Hunter, J. P., \& Csikszentmihalyi, M. (2003). The positive psychology of interested adolescents. Journal of Youth and Adolescence, 32(1), 27-35.

Lee, O. \& Anderson, C. W. (1993). Task engagement and conceptual change in middle school science classrooms. American Educational Research Journal, 30(3), 585-610.

Martin, B. H. (2014, April). Reaching out and drawing in: A conceptual framework for socially empowered learning and student engagement. Paper presented at the meeting of the American Educational Research Association, Philadelphia, PA. Retrieved from http://convention2.allacademic.com/one/aera/aera14/

Martin, B. H. (in press). Social empowerment: The evolution of a model to measure the effects of arts integration and other forms of socially empowered learning. International Journal of Arts Education.

Mbebeb, F. E. (2009). Developing productive life skills in children: Priming entrepreneurial mindsets through socialization in family occupations. International Journal of Early Childhood, 41(2), 23-34.

Organisation for Economic Co-operation and Development. (2013). PISA 2012 results: Ready to learn: Students' engagement, drive and self-beliefs (Vol. 3). Paris, France: OECD. Retrieved from http://www.oecd.org/pisa/keyfindings/PISA-2012-results-volume-III.pdf

Pope, D. C. (2001). Doing school: How we are creating a generation of stressed-out, materialistic and miseducated students. London, UK: Yale University Press.

Salomon, G. (1984). Television is "easy" and print is "tough": The differential investment of mental effort in learning as a function of perceptions and attributions. Journal of Educational Psychology, 76(4), $647-658$.

Sefton, T. G. (2006). Master of fine arts: The construction of the artist in academe (Doctoral Dissertation). Retrieved from ProQuest Dissertations and Theses database. (UMI No. NR15944)

Shernoff, D. J., Csikszentmihaly, M., Schneider, B. \& Shernoff, E. S. (2003). Student engagement in high school classrooms from the perspective of flow theory. School Psychology Quarterly, 18(2), 158-176.

Stajkovic, A. D., Lee, D., \& Nyberg, A. J. (2009). Collective efficacy, group potency, and group performance: Meta-analyses of their relationships, and test of a mediation model. Journal of Applied Psychology, 94(3), 814-828.

Wang, M. T., \& Eccles, J. S. (2012). Social support matters: Longitudinal effects of social support on three dimensions of school engagement from middle to high school. Child Development, 83(3), 877-895.

Willms, J. D., Friesen, S., \& Milton, P. (2009). What did you do in school today? Transforming classrooms through social, academic, and intellectual engagement. Toronto, ON: Canadian Education Association. Retrieved from https://www.edcan.ca/wp-content/uploads/cea-2009-wdydist.pdf 